\title{
Aspectos relevantes sobre educação sexual em grupos de terceira idade
}

\author{
Cristiane Paula Zamboni*
}

\section{Resumo}

Este trabalho objetivou realizar um estudo com idosas que frequentam grupos de terceira idade e idosas que não os frequentam, com vistas a apontar os benefícios oferecidos pelo grupo em relação à sua sexualidade. Foram realizados encontros educativos com um grupo no intuito de proporcionar reflexões sobre o tema e aplicou-se um questionário semiestruturado a dez idosas do referido grupo e dez idosas que nunca o frequentaram. As informações revelaram que as frequentadoras do grupo, embora cercadas de preconceitos e inibições, permitiram-se exteriorizar melhor sentimentos como desejos, medos, frustrações e traumas, reforçando a necessidade de haver educação sexual nesses grupos.

Palavras-chave: Sexualidade. Idoso. Educação em enfermagem.

\section{Introdução}

O idoso costuma ser visto como o declínio da juventude, uma vez que em nossa cultura é tida como parâmetro referencial de quase tudo o que é valorizado. Diante disso, depreende-se que o velho costuma ser discriminado pela sociedade, por ele mesmo e também pela família, como alguém que representa um fardo a ser carregado. Percebe-se que para ele as portas estão fechadas para novos empregos ou oportunidades de trabalho e que os jovens se mostram incrédulos, quando não irônicos e debochados, quanto ao idoso ter de uma vida sexual saudável e ativa. E para piorar, os velhos aceitam esse preconceito e envergonham-se dele ocultando essa natural capacidade. (ZIMERMAN, 1997).

A velhice é vista como uma espécie de segredo vergonhoso, do qual é indecente se falar. Sobre a mulher, a criança e o

* Graduada em Enfermagem pela Universidade Regional Integrada do Alto Uruguai e das Missões - Campus de Erechim. Especialista em Enfermagem em Traumato Ortopedia pela Universidade do Contestado. Docente do curso Técnico em Enfermagem da Escola de Educação Básica da Universidade Regional Integrada do Alto Uruguai e das Missões - Campus de Erechim. Endereço para correspondência: Rua Alemanha, 269, ap $^{\text {to }}$ 103, centro, CEP 99.700-000, Erechim - RS. E-mail: cristianez@uricer.edu.br

$\hookrightarrow$ Recebido em julho de 2008 - Avaliado em março de 2010.

$\rightarrow$ doi:10.5335/rbceh.2009.038 
adolescente, há em todas as áreas abundante literatura, porém, exceto em obras especializadas, as referências à velhice são extremamente raras. (BEAUVOIR, 1990).

A educação serve de elo para libertar o homem de sua alienação, possibilitando-lhe uma transformação crítica e criativa. (FREIRE, 1993a, 1993b). Entretanto, a educação vai além de encaminhar e instruir, pois instruir representa apenas a transmissão de conhecimentos de forma passiva, e é justamente o contrário que norteia o processo educativo, ou seja, a participação do ser na transformação da realidade, por meio de uma educação participante. Para isso acontecer a educação não pode ser unilateral, e uma proposta participativa pode ser o caminho. Na prática educativa é importante partir da realidade em que o indivíduo vive, pois o saber deve ser construído no próprio processo educativo, nas relações de igualdade entre o educando e o educador. (SANDRI, 1997).

Tendo o enfermeiro a consciência de que é um educador por excelência, tornase relevante lembrar que trabalhar com a saúde da mulher também inclui a sexualidade da mulher envelhecida. A educação sexual deve começar na infância, passar pela adolescência, continuar na vida adulta e estender-se até a velhice, quando, sobretudo, o corpo envelhecido requer cuidados e atenção.

$\mathrm{Na}$ Grécia antiga, apenas os homens livres eram considerados cidadãos, já que as mulheres, os escravos e as crianças viviam em situação inferior. Às mulheres não era permitido frequentar reuniões sociais em companhia de homens, nem lhes era permitido o desenvolvimento do intelecto. Somente homens poderiam desenvolver as capacidades intelectuais e em seus encontros a sedução podia surgir, não sendo vista como algo vergonhoso; pelo contrário, era valorizada. (ARAÚJO, 1995).

A pederastia não era uma atividade condenada, e o pederasta, por sua vez, não era considerado um desviante sexual; ao contrário, era essa uma prática aceita. Os filósofos tinham discípulos e por estes nutriam o mais profundo amor, embora algumas fontes argumentem que esse amor existia como puramente espiritual. É um tema bastante presente na antiga arte grega, onde há muitas gravuras manifestando que entre homens e meninos existia essa prática. (ARAÚJO, 1995; GREGERSEN, 1983).

A mitologia grega foi assimilada pelos romanos. O culto à deusa Vesta, protetora do lar e da humanidade, era muito importante para esse povo, o qual detinha a crença de que o bem-estar do Estado dependia do cuidado que as virgens vestais (discípulas de Vesta), dispensavam ao fogo sagrado. As vestais deveriam guardar castidade durante trinta anos, mas eram recrutadas em torno dos dez anos de idade, quando ainda era possível garantir a virgindade da menina. A virgindade da vestal constituía-se em assunto de Estado, tanto que a sua perda ou quaisquer deslizes eram punidos com a morte. Ao contrário dos gregos, os romanos valorizavam a virgindade $\mathrm{e}$ acreditavam que seria um mau augúrio casar-se com uma mulher que não fosse mais virgem. (ARAÚJO, 1995).

O cristianismo surgiu numa época em que Roma já tinha incorporado os 
valores gregos no que se refere à harmonia e à beleza e, no plano das ideias, o estoicismo estava na moda. Essa época se caracterizou pela intensa repressão à sexualidade e pela extrema valorização da virgindade e da castidade. São Paulo pregava que era bom ficar em estado de castidade como ele, mas que aquele que não conseguisse deveria se casar. $\mathrm{O}$ apóstolo condenava a continência prolongada entre os casados, porque justificava espaço para a tentação. (GREGERSEN, 1983).

A sexualidade começou a ser reprimida justamente pela má interpretação de alguns valores filosóficos. Percebe-se que a virgindade passou a ser extremamente valorizada e, consequentemente, também a castidade. As pessoas sentiam-se amendrontadas e vigiadas, porque o homem não queria se casar com uma moça que não fosse mais virgem, a qual, por sua vez, tinha de preservar sua virgindade para que pudesse se casar. Então, a sexualidade fora do matrimônio e o sexo por prazer traziam o estigma do pecado.

Há diversos equívocos que marcam a forma como a questão sexual foi articulada no Ocidente. A interpretação da filosofia platônica, neoplatônica e estoica pelos pensadores cristãos da época deu um sentido diferente à alma, ao qual Platão se refere. No pensamento grego, alma é intelecto e vontade, ao passo que para o cristão é espírito, a essência da vida. Aí se encontra, pois, a raiz do enfoque do corpo como algo que atrapalha o desenvolvimento da alma. Para os gregos, não havia a ideia de pecado; o que valorizavam era a harmonia do ser. (ARAÚJO, 1995).
A repressão sexual e a exclusão das mulheres das decisões sociais, bem como a submissão imposta naquela época, acarretaram ao sexo feminino sérias consequências, sendo algumas até hoje mal resolvidas, ou reprimidas em seu íntimo.

O Renascimento marcou uma fase de transição entre a Idade Média e a Idade Moderna. Nesse período, as pessoas passaram a pensar mais em si mesmas como indivíduos e a aceitar como naturais seus desejos, instintos e impulsos. O grande herói da época foi o artista, destacando-se Leonardo da Vinci, Michelangelo, Rafael, Boticelli, dentre os quais muitos eram filhos ilegítimos e cujas vidas foram marcadas por grande liberdade sexual. Desse período emerge um declínio da espiritualidade, que esteve ligado à baixa reputação espiritual da Igreja.

Roma vivenciava uma fase de extrema liberdade sexual e, em 1494, a sífilis apareceu na Europa, tornando-se uma catástrofe para a humanidade. Foi considerada um castigo divino como punição à promiscuidade. (ARAÚJO, 1995).

O surgimento da Reforma Protestante teve grande serventia para alertar a Igreja sobre o perigo do desregramento. O Concílio de Trento objetivou reafirmar a doutrina católica, questionada pelos reformadores protestantes, principalmente em assuntos que se referiam ao casamento e ao sexo. Com a evolução da pastoral católica e do sacramento da confissão, a Contrarreforma dedicou-se, em todos os países católicos, a acelerar o ritmo da confissão e tentou impor regras mais rígidas, atribuindo, assim, cada vez mais importância à penitência, 
em desfavor de alguns pecados, como as insinuações da carne. (ARAÚJO, 1995).

O século XVII daria início a uma época de repressão, dessa vez advinda das sociedades burguesas. Falar sobre sexo seria, a partir desse momento, mais difícil. Controlar os discursos, apagar o que era dito e extinguir as palavras que se faziam presentes por meio de proibições foram as medidas tomadas para que se impusesse o silêncio e a censura. (FOUCAULT, 1988).

A população idosa vem aumentando consideravelmente, mas a percepção que a sociedade e o ser humano têm do amor e da sexualidade na velhice não sofreu grandes mudanças com o passar dos tempos. Gozando de boa saúde, homens e mulheres continuam, assim como no passado, sem maiores expectativas amorosas nessa etapa da vida e permanecem "castrando-se" muito antes do tempo necessário. Os homens, que pouca importância deram a sua realização afetiva, escondem-se atrás de preconceitos impostos pela sociedade para justificar seu desinteresse. (FUCS, 1993).

A sexualidade na terceira idade não é melhor nem pior que a dos jovens; apenas passa por modificações, referentes às experiências acumuladas durante as etapas da vida. A falta de conhecimento dos benefícios dessas experiências leva a que insistam em manter uma expectativa bastante semelhante à de quando eram jovens, o que é incompatível com as mudanças fisiológicas que ocorrem com o envelhecimento. (MATTIODA et al., 1998).

A sexualidade não é só uma atividade sexual, mas também a interação de aspectos físicos, emocionais e intelectuais, espirituais e sociais de um indivíduo, homens ou mulheres. O profissional de saúde detém a responsabilidade de promover programas de educação sexual geriátrica e o dever de aceitar a proximidade física dessas pessoas, resgatando o fator social, incentivando $o$ desenvolvimento da auto-estima, enfim, buscando melhorar sua qualidade de vida. (VIEIRA, 2004).

\section{Metodologia}

O caminho percorrido configurase como uma abordagem qualitativa, desenvolvida em dois momentos. O primeiro, com um grupo de terceira idade chamado Universidade Sem Limites, o qual se concretizou nas dependências da Universidade Regional Integrada do Alto Uruguai e das Missões - Campus de Erechim no período de julho de 2008. Foram realizados cinco encontros, com uma média de 2 horas cada.

Os encontros foram desenvolvidos com uma dinâmica diferente para cada grupo, proporcionando às participantes momentos para expressar sua criatividade, expor ideias, pensamentos e reflexões, bem como quebrar o tabu e o medo de refletir sobre sexo e sexualidade.

$\mathrm{O}$ segundo momento compreendeu a coleta de informações por meio de entrevista semiestruturada a dez participantes do grupo e a dez idosas que não participaram de nenhum encontro de grupos de terceira idade, as quais foram convidadas informalmente, tanto no grupo como fora dele. Todas as entrevistadas contavam com mais de sessenta anos, marco conceituado pela 
Organização Mundial da Saúde para o início da terceira idade.

A aplicação da entrevista aconteceu com data e hora agendada nas residências das entrevistadas e seus relatos foram gravados em fita cassete, com o consentimento das participantes, sendo transcritos na íntegra e posteriormente analisados. Este trabalho foi aprovado pelo Comitê de Ética em Pesquisa da Universidade Regional Integrada do Alto Uruguai e das Missões - Campus de Erechim, sob o $\mathrm{n}^{\circ}$ 047/PPH/2008.

\section{Resultados e discussão}

As dez entrevistadas que participaram do estudo frequentadoras do grupo possuem entre 62 e 73 anos; seis são casadas e quatro, viúvas. Oito praticam a religião católica; uma é israelita e uma, espírita. Nove são do lar e uma, escritora. Três possuem o ensino fundamental incompleto; duas, o ensino médio incompleto; três, o ensino médio completo; uma, terceiro grau incompleto e outra, terceiro grau completo.

As outras dez entrevistadas que participaram do estudo, que nunca participaram de nenhum encontro de grupo de terceira idade, possuem entre 60 e 72 anos. Cinco são casadas; quatro, viúvas e uma, separada. Nove praticam a religião católica, e uma, a espírita. Sete são do lar; uma é professora; uma, cozinheira e uma, proprietária de casa de estudante. Uma delas nunca frequentou a escola; seis possuem o ensino fundamental incompleto; duas, o ensino médio completo e uma, o terceiro grau completo. A categorização em função da habitação, filhos, relacionamento familiar e casamento, por estarem efetivamente interligados, foram analisados em conjunto. Diante disso, pode-se inferir que o vínculo afetivo é o mais constante na vida das pessoas quando atingem a terceira idade, pois os filhos já estão cuidando de si, envolvidos com outras preocupações, ocupados com suas famílias já constituídas. A sexualidade é uma poderosa arma a ser usada em prol do companheirismo, fundamental nesta fase da vida. (PAPALIA; WENDKOS, 1997).

Os casais que têm uma vida afetiva bem estruturada, inconscientemente, influenciam seus filhos em suas escolhas afetivas, os quais também mantêm um relacionamento familiar afetivo e respeitoso, maior do que as famílias em que o casal não se compreende.

[...] Ele tinha o pior defeito que um homem pode ter, a bebida. Ele voltava sempre tarde da noite. Atrapalhou nosso relacionamento homem-mulher e também com os filhos. Por causa disso houve nossa separação, mas o relacionamento com os filhos não melhorou. (Não frequenta grupo)

É de fundamental importância a conscientização de que a educação sexual precisa ser realizada nas escolas, na família, nos clubes, para no futuro não haver tanto despreparo para o exercício de uma atividade marcante, frequente e duradoura na vida do ser humano. (PAPALÉO NETTO, 2005).

Percebeu-se que as entrevistadas não obtiveram nenhum tipo de informação ou educação a respeito de sexo e sexualidade; apenas aprenderam com a vida. Algumas, na iminência do 
casamento, receberam informações de amigas ou de uma irmã mais velha.

[...] Eu até já sabia um pouco. A mãe ajudou, ela me explicou como a gente tinha que fazer com o marido. Ela dizia que não era pra gente dizer não pro marido, porque ele ia procurar em outro lugar. Eu nunca disse não pro meu marido. (Integrante do grupo)

[...] A única coisa que eu fiquei sabendo foi através de uma carta que eu recebi de umas amigas sobre como era a lua-de-mel. Ninguém falava pra gente como é que engravidava. (Não frequenta grupo)

Quando questionadas sobre a existência de desejo, pôde-se constatar que houve uma diminuição do desejo, isto é, continuam sentindo-o de maneira diferente, com menor frequência e intensidade.

Uma boa parte dos idosos relatou que o desejo sexual aumenta nesta fase da vida, pois o tempo para se cortejarem e se agradarem é maior, permitindo uma maior aproximação entre os casais. Por outro lado, os casais que não tiveram uma vida feliz dificilmente conseguem se encontra na velhice. (FUCS, 1993).

[...] Existe desejo, sim. Agora é melhor. Hoje não tem hora, se dá vontade às 4 da tarde, nós vamos. Às vezes eu convido, às vezes ele. Eu tomo banho e pergunto pra ele se ele tá disposto e ele vem bem ligeiro. (Integrante do grupo)

[...] Depois da menopausa meu desejo aumentou, parece que tenho 20 anos de novo. (Não frequenta grupo)

Outro dado importante para a valorização deste estudo foi a ocorrência de orgasmo. $\mathrm{O}$ orgasmo é consequência de uma boa relação sexual e é tão valorizado em nosso cotidiano que alguns meios de comunicação já criaram inúmeros programas e reportagens referentes ao tema. (PAPALIA; WENDKOS, 1997).

[...] Eu sempre tive, graças a Deus, porque tem muita mulher que não sabe o que é ter. É verdade ou não é? (Integrante do grupo)

[...] Meu marido sempre foi muito paciente comigo, porque naquela época a gente casava virgem. Ele sempre perguntava se eu sentia orgasmo. (Não frequenta grupo)

Nesse sentido, todas as entrevistadas, independentemente do estado civil, consideram o sexo e a sexualidade fatores determinantes na qualidade de vida do ser humano, o que se justifica pelos fragmentos de fala:

[...] Eu acho que a sexualidade na terceira idade é tão importante quanto à sexualidade dos jovens. (Não frequenta grupo)

[...] Acho que quem tem companheiro seja casado ou não, tem uma vida mais completa, porque o sexo é um complemento para a felicidade. (Integrante do grupo)

A repressão sexual vivenciada na juventude tanto pelas mulheres como pelos homens contou com a prevalência do casamento por apresentação. Quando chegava a hora de o homem se "acomodar", ele era apresentado a uma moça num baile ou em alguma reunião de família. Ela se casava para conquistar um pouco mais de liberdade e cumprir seu papel de mulher. Era seu dever agradar e servir o marido, desempenhar as tarefas da casa, cuidar bem dos filhos e cumprir com suas obrigações no leito conjugal “[...]. Praticamente não existia nenhum tipo de educação sexual, o que se transmitia era apavorante: os homens eram violentos, $\mathrm{e}$ à mulher, restava a opção de submeter- 
se sem escândalos." (FRAIMAM, 1994). A falta de orientações, de conhecimento do próprio corpo e, até mesmo, a falta de diálogo sobre assunto foram explicitadas pelo depoimento a seguir:

[...] Até poucos dias antes de eu casar, eu pensava que o nenê nascia pelo umbigo. Daí uma amiga me disse por onde que nascia e eu não acreditei. Pois eu peguei um espelho e fui olhá, e eu achava que não podia porque era tão pequenininho. (Integrante do grupo)

Ao sonhar com um príncipe encantado, as moças não imaginavam apenas um rapaz, bonito, honesto e trabalhador, que não deixasse faltar nada em casa, mas alguém com quem pudessem conversar, um companheiro para passeios e, especialmente, um ser capaz de amálas. (FRAIMAM, 1994). O fragmento a seguir relata as frustrações sofridas pela mulher naquela época.

[...] O casamento era o sonho de qualquer mulher, e muitas vezes este sonho virava uma frustração, porque não correspondia às expectativas. (Não frequenta grupos)

A mulher era criada num meio onde sua opinião não tinha valor nem fundamento; apenas os homens tomavam as decisões. Para os homens da época, a mulher existia apenas para servir e obedecer. (FRAIMAM, 1994). Por outro lado, algumas mais ousadas conseguiram vencer essas barreiras desafiando a situação que lhes era imposta, além de valorizar sua autoestima.

[...] Era tudo o marido que decidia, às vezes, até na vida da gente. (não frequenta grupos)

[...] Eu consegui vencer a submissão, fui estudar, terminei minha faculdade. Ele tava sempre de bico torto comigo, mas eu fui adiante, às vezes ele dormia no sofá de bravo. (Integrante do grupo)

$\mathrm{O}$ esclarecimento por meio da educação, do debate exaustivo e contínuo pode fazer chegar às pessoas de idade a alegria de um entrosamento que muitas vezes nunca foi possível antes, pois o tema sexualidade é tão importante para elas como pessoas como pela possibilidade de orientarem filhos e netos. (FUCS, 1999). Sobre a importância em se discutir a sexualidade na terceira idade as entrevistadas referiram:

[...] Em toda a idade é importante se falar em sexualidade. Nós, como somos mais de idade, temos que dialogar com os mais jovens sobre aids e gravidez. Nós temos a obrigação de orientar. (Integrante do grupo)

[...] O que estamos aprendendo agora sobre sexualidade, deveríamos ter aprendido na infância, na adolescência. Na época sabíamos que praticar sexo era pecado mortal. Sexo só era permitido entre os casais, pra procriar. Também praticar sexo evitando filhos era condenado pela Igreja. Sexualidade é um aperto de mãos, um beijo, um carinho, um sorriso. [...] Sexo na terceira idade pratica-se sem a preocupação de engravidar, pode-se sussurrar à vontade sem a preocupação de que os filhos ouçam [...]. (Integrante do grupo)

Nesse contexto, os grupos têm a função de promover uma reflexão conjunta. A função primordial de um grupo é possibilitar aos integrantes a vivência de participação como membro de um grupo, cuja essência significa propiciar um espaço para a livre discussão do que aflora dessa experiência compartilhada de aprendizagem, tanto no que diz respeito aos sentimentos despertados pelos próprios temas que estão sendo aborda- 
dos, quanto às emoções emergentes das interações. (OSÓRIO, 2000).

\section{Considerações finais}

Os resultados evidenciaram que, para as idosas participantes do grupo de terceira idade, este estudo, além de proporcionar reflexões e conhecimento sobre o tema, permitiu-lhes adquirir liberdade e desinibição a fim de exporem suas ideias e anseios. A troca de experiências também permitiu a exteriorização de seus desejos, sentimentos, traumas, frustrações e tabus.

Porém, nas idosas que nunca estiveram num grupo de terceira idade e que, consequentemente, não tiveram a oportunidade de refletir, de vivenciar, e ouvir outras experiências, bem como discutir sobre essas, constatou-se grande dificuldade quanto à obtenção de informações, pois muitas vezes as respostas foram monossilábicas, cercadas de pudor e inibição.

Quando se fala em educação, logo vem a mente criança, e é compreensível que assim seja, pois é a etapa ideal para que as sementes sejam plantadas. No entanto, não há como se limitar a essa faixa etária, principalmente quando se trata de educação sexual. As pessoas que hoje vivem a sua terceira idade não foram preparadas para uma sexualidade sem traumas, preconceitos e tabus. Nesse sentido, o estudo veio comprovar a necessidade da educação sexual para os idosos a fim de lhes proporcionar qualidade em seus relacionamentos, bem como, geralmente, o resgate de sua afetividade.
O envolvimento com um grupo, para o idoso, pode funcionar com um canal de comunicação, propiciando o emergir de uma ressocialização, visto que se sentem reconhecidos, falam um mesmo idioma emocional, criam um espaço único e podem compartilhar seus anseios e dificuldades, ao mesmo tempo em que se dão conta de que outros também possuem problemas.

O convívio harmonioso, a franqueza, a troca, o conhecimento e, sobremaneira, o (re)despertar do lado afetivo-emocional significam o combustível para tornar a caminhada menos árdua.

Relevant aspects on the importance of sexual education in elderly age groups

\section{Abstract}

The purpose of this work was to conduct a study with elderly women, who either take part in Elderly Age Groups or don't, in order to point out the benefits for their sexuality offered by the group. There were educational meetings with one of the groups, so that they could think and reflect on the theme. Besides, a semi-structured questionnaire was applied to twenty elderly women, ten of them who took part in the group and the other ten who didn't. The information obtained revealed that despite having some prejudice and inhibitions, the ones who took part in the group let themselves freely express their desires, fears, frustrations and traumas, as well as the same women pointed out the necessity of having sexual education in those groups.

Key words: Sexuality. Elderly. Education. Nursing. 


\section{Referências}

ARAÚJO, M. L. M. Moral sexual: um estudo do pensamento católico e suas relações com a sociedade brasileira. 1995. Tese (Doutorado em Filosofia) - Programa de Pós-Graduação em Filosofia da Universidade Gama Filho, Rio de Janeiro, 1995.

BEAVOIR, S. A velhice. Rio de Janeiro: Nova Fronteira, 1990.

FOUCAULT, M. História da sexualidade I: a vontade de saber. Rio de Janeiro: Graal, 1988.

FRAIMAM, A. P. Sexo e afeto na terceira idade: aquilo que você quer saber e não teve com quem conversar. São Paulo: Gente, 1994.

FREIRE, P. Pedagogia do oprimido. 21. ed. São Paulo: Paz e Terra, 1993a.

\section{$1993 \mathrm{~b}$.}

Política e educação. São Paulo: Cortez,

FUCS, G. B. Homem-mulher: encontros e desencontros. 2. ed. Rio de Janeiro: Rosa dos Tempos, 1993.

FUCS, G. B. A educação sexual na idade adulta e na velhice. In: RIBEIRO, M.; EGYPTO, A. C. (Org.). O prazer e o pensar: orientação sexual para educadores e profissionais de saúde. São Paulo: Gente-Cores, 1999. v. 1.

GREGERSEN, E. Práticas sexuais: a história da sexualidade humana. São Paulo: Rocca, 1983.

MATTIODA, D. D. et al. Sexualidade na terceira idade. Sensu: Pós-Graduação em Revista, Caxias do Sul, v. 1, n. 1, p. 27-45, 1998.

OSÓRIO, L. C. Grupos: teorias e práticas - acessando a era da grupalidade. Porto Alegre: Artmed, 2000.

PAPALÉO NETTO, M. Gerontologia: a velhice e o envelhecimento em visão globalizada. São Paulo: Atheneu, 2005.
PAPALIA, D. E.; WENDKOS, O. Desenvolvimento humano. 7. ed. Porto Alegre: Artes Médicas, 1997.

SANDRI, J. A. Prática assistencial de enfermagem à pessoa idosa e seu familiar, com vistas ao resgate de sua cidadania, utilizando a teoria de Betty Neuman. Florianópolis: [s. e.], 1997.

VIEIRA, E. B. Um guia teórico-prático para profissionais cuidadores e familiares. 2 . ed. Rio de Janeiro: Revinter, 2004.

ZIMERMAN, D. E. Como trabalhamos com grupos. Porto Alegre: Artes Médicas, 1997. 